\title{
Learning Together: Sharing Circles in Rural Alaska on Cancer Education Priorities for Youth
}

\author{
Katie Cueva ${ }^{1}\left[\right.$ ] Jennifer Schmidt ${ }^{1} \cdot$ Melany Cueva $^{1}$
}

Accepted: 15 July 2021 / Published online: 27 July 2021

(c) American Association for Cancer Education 2021

\begin{abstract}
Culturally relevant health promotion with youth is an opportunity to reduce health inequities in cancer. This manuscript describes sharing circles conducted with three communities in the Northwest Arctic region of Alaska. The circles were designed to begin understanding community priorities and lay the foundation to develop culturally relevant cancer education. The project was guided by the principles of Community-Based Participatory Action Research (CBPAR), honored Indigenous ways of knowing, and was grounded in Empowerment Theory. The project team facilitated 13 sharing circles in November 2019 in three communities in the Northwest Arctic. There were a total of 122 participants, including teachers/school staff (31\%), community members (30\%), high school students (23\%), and health professionals (16\%). The circles explored youth knowledge, perceptions, questions, concerns, and hopes for cancer information; community members' desires for youth knowledge about cancer; and how teachers would like content to be formatted for effective inclusion in their classrooms. Common themes from the sharing circles included a desire for information on cancer prevention (all 13 sharing circles) and a need for information on cancer risk factors (12). In most sharing circles, participants shared that cancer information for youth should include stories like those of local people, cancer survivors, and role models (11), visuals (8), and local data and statistics (8). In addition, teachers and school staff in all communities wanted an online resource for teaching about cancer in their classrooms that had short videos/visuals with related lesson plans and activities.
\end{abstract}

"If I learn, I can reduce the chance of getting cancer in the future."

Keywords Alaska Native $\cdot$ Health promotion $\cdot$ Disparities $\cdot$ Cancer $\cdot$ CBPR $\cdot$ Qualitative

\section{Background}

Cancer is the second leading cause of death in the United States and was projected to cause over 600,000 deaths in 2020 [1]. Cancer has been the leading cause of death in Alaska since 1993 and is the leading cause of death for Alaska Native people [2]. Alaska Native people are disproportionately burdened, both by cancer mortality and incidence, as well as associated risk factors [3-5]. In 2017, the cancer mortality rate for Alaska Native people was more than $60 \%$ higher than for Non-Native people in Alaska [6]. Among Alaska Native people, lung, colorectal, and breast cancer are the most commonly diagnosed cancers, which

Katie Cueva

kcueva@alaska.edu

1 Institute of Social and Economic Research, University of Alaska Anchorage, 3211 Providence Dr., Anchorage, AK 99508, USA all have modifiable behavioral risk factors [4, 5]. Lung and colorectal cancer are the first and second leading causes of cancer death among Alaska Native people, with incidence rates that are 1.5 and 2.3 times higher, respectively, than for Non-Hispanic Whites in Alaska [7]. Health promotion efforts to encourage healthy behavior change present an opportunity to reduce cancer risk.

Health behaviors like physical inactivity, unhealthy diet, and obesity increase cancer risk, a fact many Americans do not realize [8]. However, racial and ethnic minority groups bear a disproportionate burden of these risk factors. In the Alaska context where this work is focused, in 2018, 38.6\% of Alaska Native adults reported current smoking (compared with $14.6 \%$ of non-Hispanic White adults in Alaska). In 2014-2018, 36.3\% of Alaska Native adults reported being obese, significantly higher than $31 \%$ of White adults in Alaska [9].

Health promotion efforts to reduce cancer risk factors have the potential to mitigate the disparities impacting 
Alaska Native people. Previous cancer education with, and for, Alaska Native people has led to self-reported decreases in cancer risk factors and improved self-efficacy to share cancer-related health information $[10,11]$. The disparities between Alaska Native and White Alaskan adults are not intractable; in part due to health promotion efforts, the percentage of Alaska Native adults who have reported receiving a breast, cervical, or colorectal cancer screening recently attained parity with rates for both Alaska White adults and U.S. White adults [12-14].

There is little cancer education that is designed to be culturally relevant and developed in partnership with Alaska Native people $[10,11,15,16]$. However, studies show that culturally relevant educational programs have greater success in supporting desired health outcomes such as reduced youth smoking [17]. By incorporating relevant curricular content in ways that information is desired to be shared, health promotion has greater potential to impact positive change. Prior to this work, a culturally relevant cancer educational curriculum for Alaska Native youth had not been developed. However, due to the many factors influencing the especially high cancer rates among Alaska Native people, creating such a curriculum could contribute to lowering mortality rates. Culturally tailored health education programs can aid in spreading awareness of ways to reduce cancer risk, relevant cancer statistics, recommended screening exams, activities, experiences, and stories about cancer and its impact on the participating communities. Including Indigenous youth is especially critical as a target population for cancer education, as Indigenous youth have the potential to reduce cancer risk among future generations, as well as communicate cancer risk reduction messages within their communities [18]. By developing health promotion programs that incorporate culturally relevant concepts, the education has the potential to be more effective [19]. For example, in a study of suicide interventions developed for American Indian and Alaska Native people, the best responses came from programs that incorporated culturally relevant curriculum. In addition, participants in the study mentioned above felt it was their duty to share their lived experiences in order to help others [20]. Including the lived experiences of community members and providing a platform and opportunity for community members to share their stories creates an opportunity for community involvement of all ages.

This manuscript describes sharing circles conducted with three communities in the Northwest Arctic region of Alaska to begin understanding community priorities and lay the foundation to develop culturally relevant cancer education. A project team member from the Institute of Social and Economic Research at the University of Alaska Anchorage was involved in work in the Northwest Arctic on subsistence and climate change but heard repeated concerns from community members about cancer and youth and the need to increase education. An individual with expertise in cancer education at the same institute had heard similar concerns from previous cancer education work and the duo facilitated sharing circles in the Northwest Arctic to investigate concerns and, if relevant, identify the community's priority areas for youth cancer education. The sharing circles specifically recruited high school students, community members, high school teachers and school staff, and health professionals. Hosting sharing circles with participating communities laid the foundation for cancer education to incorporate culturally relevant content, cultural values, and Indigenous knowledge to promote cancer prevention and control.

\section{Theoretical Framework}

The sharing circles were conducted as the first step in developing a cancer education program focused on empowering individuals to change behavior and shift social norms to reduce cancer risk and control cancer in the Northwest Arctic. The project was reviewed by the University of Alaska Anchorage Institutional Review Board (\#1416366-8) and Maniilaq Association, the tribal non-profit corporation in the Northwest Arctic that manages health, tribal, and traditional assistance programs, as well as social services for the region. This project was guided by the principles of CommunityBased Participatory Action Research (CBPAR) that honors Indigenous ways of knowing and was grounded in Empowerment Theory to provide culturally respectful education that empowers individuals and inspires wellness activities. This work was also conducted in alignment with the proposed framework for creating culturally relevant online cancer education developed from work with Alaska's Community Health Aides and Community Health Practitioners (CHA/ Ps) [15].

CBPAR is a partnership between communities and academics/researchers that focuses on locally relevant issues, builds on community strengths, and realizes social change to reduce inequities [21,22]. This framework guided the collaboration of the project team during the sharing circles. In alignment with the CBPAR principles to "promote colearning and capacity building" and conduct work in "collaborative, equitable partnerships," the project team sought to build relationships with community members and recruit a community advisory board to guide project development. Indigenous Ways of Knowing, while diverse and heterogeneous, often include incorporating "affective and subjective elements, and learning within the context of relationships, observations, and experiences" [15, 23, 24]. Consequently, this project sought both to seek out information and to build relationships with community members and potential collaborators in this work. 
Empowerment theories are both a foundation of CBPAR and a natural extension of CBPAR. Paulo Freire's Popular Education is a theoretical root of CBPAR and advocates for empowering education that leads to social transformation an idea identified as an effective health education strategy [25]. Empowerment-oriented approaches are also fundamental in working with Indigenous communities. Historical trauma linked to the colonization of Indigenous peoples has disrupted traditional food systems and cultural practices that facilitate physical activity, healthy eating, and limited tobacco use and is linked by some Indigenous researchers to contemporary cancer disparities [26]. Acknowledging historical trauma and its impacts, CBPAR theorists advocate that work with Indigenous communities focus on selfdetermination and empowerment [27], an approach actualized by this project's focus on cultural-relevancy and cultural strength. Intertwined with self-determination, empowerment is a contextual, participatory process that advances social justice and redistributes power to increase control [28]. Empowerment-oriented approaches are designed to:

“...enhance wellness while they also aim to ameliorate problems, provide opportunities for participants

to develop knowledge and skills, and engage profes-

sionals as collaborators instead of as authoritative experts." [28]

Empowerment Theory is a framework that guides these approaches, and CBPAR "exemplifies empowering processes," including working with the community and building capacity [29]. Youth are uniquely situated to empower health behavior change due to their potential to live positive health behaviors and role model that behavior as future elders and leaders of the next generations of community members.

A proposed framework for culturally relevant online cancer education with and for Alaska Native people was proposed in 2018 and included four central constructs: (1) collaborate with potential learners and community members to develop and refine education; (2) deliver content in relevant ways, such as through personal stories and visuals; (3) contextualize content to learners' unique experiences and cultures; and (4) allow space for relationship building and connections to allow individuals to learn from/with each other [15]. This development project begins with the first construct by collaborating with potential learners and community members to identify both priorities for culturally relevant content delivery, and ways to allow for content to be appropriately contextualized with space for relationship building.

The sharing circles described in this manuscript were designed to involve participants as professional collaborators from these first steps in articulating what culturally relevant cancer education for youth in Northwest Arctic may look and feel like. The sharing circles were conducted to explore the cancer education priorities of community members in the three participating communities and develop relationships to guide potential future youth cancer education creation.

\section{Methods}

A CBPR approach of community engagement includes actively listening to key stakeholders. Consequently, sharing circles were facilitated in each of the three participating communities. Sharing circles are a traditional way of engaging Indigenous community members [30]. Through existing relationships with individuals in the region, and through outreach to Maniilaq Association and school staff, partners were recruited to assist in advertising the sharing circles and arranging separate times to meet with community members, high school teachers/school staff, health professionals, and high school students. The project team traveled to each of the three communities in the Northwest Arctic Borough (see Fig. 1) to facilitate the sharing circles, offering snacks and drinks and a $\$ 50$ gift card to each participant as a thank you to honor their contributions. Two of the participating communities were relatively small, with less than a thousand residents each, while one community was relatively large, with a population between 2,500 and 5,000 residents. While in each community, the project team finalized, adjusted, and added sharing circle times when needed to accommodate community members' requests. They advertised the sharing circles via word of mouth, emails to key stakeholders, through flyers, and over the radio. The circles explored youth knowledge, perceptions, questions, concerns, and hopes for cancer information; community members' desires for youth knowledge about cancer; and how teachers would like content to be formatted for effective inclusion in their classrooms.

Each sharing circle began with introductions and, in response to community partner requests, a brief presentation by the project team on cancer statistics in the region, including risk factors for cancer, leading causes of cancer incidence and mortality, and comparison of regional rates to other regions in Alaska and other states in the United States. Following this introduction, the project team duo facilitated an informal conversation guided by the following questions: (1) Is there a need for cancer education in your community? (2) What do you think high school students should learn about cancer? (3) What would be the best ways for youth in your community to learn about cancer? / What would you like to learn about cancer? (4) What else should we know as we plan cancer education for youth? (5 - only asked of teachers and school staff) What learning materials would be most useful for you to use in your classroom?

Notes were taken by one of the project team members during each sharing circle where participants could see them 


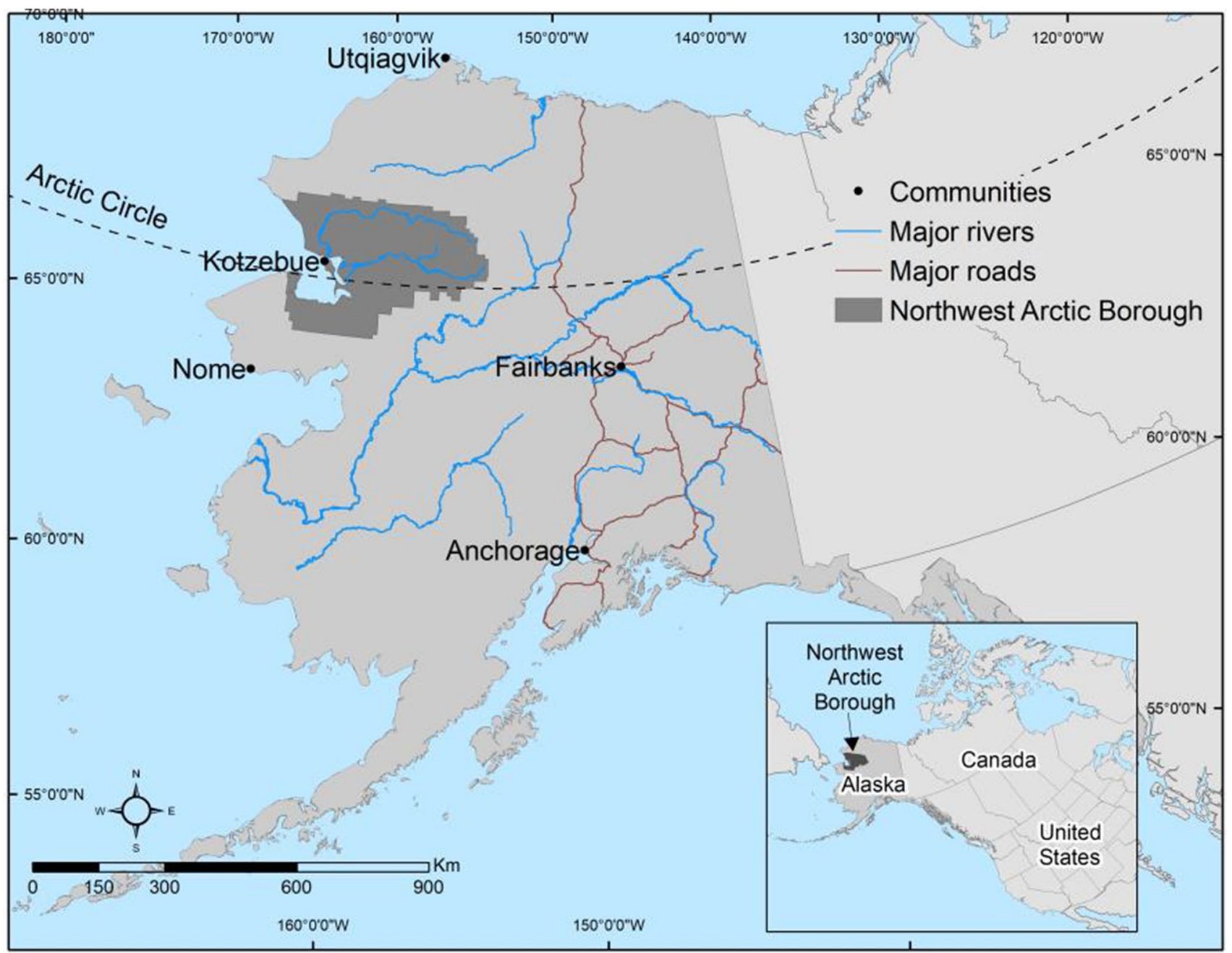

Fig. 1 Northwest Arctic Borough in Alaska

- such as on flip-chart paper or on a whiteboard. Prior to the end of each sharing circle, a project team member read the notes out loud to the participants and invited comments/edits to those notes. The meetings were not otherwise recorded. These notes were then typed up, independently coded by two project team members in Atlas.ti to identify common themes across sharing circles and within communities. Codes emerged from analysis of the meeting notes by each team member independently. A codebook was then created by the two coders through consensus. In addition, verbatim comments within each type of sharing circle (youth, community, etc.) were categorized by question in Microsoft word to summarize responses.

\section{Respondents}

The project team facilitated 13 sharing circles in November 2019 , with a total of 122 participants. Three sharing circles were held with high school students and three with teachers/school staff, one in each community. Two sharing circles were held with health workers, while health workers declined to participate in a sharing circle in the third community. Five sharing circles were held with community members, two circles in two of the communities due to community requests, and one in the third community. Participants included teachers/school staff (31\%), community members (30\%), high school students (23\%), and health professionals (16\%) (see Table 1).

\section{Findings}

Common themes from the sharing circles included desires for education on cancer prevention (mentioned in all sharing circles) and a need for information on cancer risk factors (mentioned in 12 of the 13 sharing circles). In most sharing circles, participants stated that cancer information for youth should be communicated through stories, such as of 
Table 1 Demographic characteristics of sharing circle participants

\begin{tabular}{ll}
\hline Demographic & $\begin{array}{l}\text { Sharing cir- } \\
\text { cle respond- } \\
\text { ents } \\
\text { N }(\%)\end{array}$ \\
\hline Total & $122(100 \%)$ \\
Gender & \\
Female & $71(58 \%)$ \\
Male & $50(41 \%)$ \\
Age & \\
$14-19$ & $29(24 \%)$ \\
$20-29$ & $19(16 \%)$ \\
$30-39$ & $20(16 \%)$ \\
$40-49$ & $7(6 \%)$ \\
$50-59$ & $23(19 \%)$ \\
$60-69$ & $14(11 \%)$ \\
$70+$ & $4(4 \%)$ \\
Role & \\
High school student & $28(23 \%)$ \\
Teacher/school staff & $38(31 \%)$ \\
Health professional & $19(16 \%)$ \\
Community member & $37(30 \%)$ \\
Community & \\
Small community A & $42(34 \%)$ \\
Small community B & $46(38 \%)$ \\
\hline & $34(28 \%)$ \\
\hline
\end{tabular}

local people, cancer survivors, and of role models (11 sharing circles), visuals (8 sharing circles), and local data and statistics ( 8 sharing circles). In addition, teachers and school staff in all communities felt that an online platform that had a short video/visual followed by a lesson plan would be useful cancer education material that could be most easily disseminated. Information by type of sharing circle and question is broken down in more detail below.

\section{Sharing Circles with High School Students}

Students thought that it was important to learn about cancer: "Yes, we need to get informed and be more aware of it." Students said they knew that cancer could kill and that people of any age can get it. In at least 2 of the 3 sharing circles held with youth (one in each community), students said that topics they wanted to learn about included smoking and its impacts on cancer, what causes cancer, how to prevent cancer, interesting statistics about cancer, information on smoking/marijuana and cancer, types of cancer, and coping skills for dealing with trauma for themselves and their friends and family. In at least 2 of the 3 sharing circles, students also described that cancer education would be interesting for them if it included stories from youth and adult role models, as well as cancer survivors in their communities hands-on projects like making posters or doing experiments, relevant statistics, local information, and visuals such as slideshows or movies on different types of cancers.

\section{Sharing Circles with Health Professionals}

Health workers in two communities participated in sharing circles, expressing that they wanted youth to learn about cancer prevention such as screening exams, healthy foods, HPV vaccine, causes of cancer, and the impacts of tobacco use on health as well as the financial cost of tobacco use. They noted that youth might need guidance on how to ask for tobacco cessation counseling or information on getting the HPV vaccine with different parent preferences. The health workers also described a need for teaching positive coping strategies and said, "don't keep information from them just because they're younger."

Health workers thought that the best ways for youth to learn about cancer included through stories, either recorded or in person, such as of elders, cancer survivors, celebrities, or a basketball coach telling their story at a basketball tournament. Health workers also asked for youth to learn through hands-on experiences or props - such as manipulating pigs' lungs to learn about smoking, or creating science projects to share at health fairs.

Health workers shared that people in their communities were afraid of cancer and that it had a large negative emotional impact. One person discussed that there was a traditional teaching that if someone did not understand something that they should not talk about it, which had contributed to silence around cancer, although that was now changing. Health workers also noted that there was stigma around cancer, that many youth believed marijuana was medicinal, and that reading material for high school students should be at a $6^{\text {th }}$ grade reading level or below. Health workers also felt that there were limited resources in their communities — "nothing to bring cancer to the forefront."

\section{Sharing Circles with Community Members}

In response to community requests to host additional sessions, five sharing circles were held with community members. Community members shared that kids needed "to be educated [about cancer] because there are fewer elders around." Participants in at least 3 of the 5 sharing circles said that they wanted youth in their communities to learn about tobacco and cancer, types of cancer, cancer prevention such as eating local traditional foods, exercising, avoiding sugary drinks, and learning how to cook healthy meals.

Community members in all sharing circles felt that one of the best ways for youth to learn was through visuals/videos, including of local people, or on relevant info like smoking and rates of cancer in different regions. In four of the sharing 
circles, community members shared that stories were a way for youth to learn about cancer, including stories of role models, cancer survivors, Community Health Aides/Practitioners, elders, and celebrities. In three of the sharing circles, community members mentioned engaging youth in cancer education through social media platforms.

Community members also shared that there were few if any resources on cancer in their communities: "No, you're the first ones that have come." Community members noted that high school may be too late for changing behaviors such as smoking, and that "kids younger than high school age are curious about cancer." Community members also mentioned that there was stigma about going to the clinic, especially for men; "lots of women go to the clinic but few men," as "some people are afraid of going to the clinic - some shame in going." Additionally, community members expressed a need for more health resources in their communities, wanting an option for a second opinion if they did not feel the health provider was accurate, and wanting increased capacity for cancer screening and treatment in the region, particularly as "some people are afraid of going to Anchorage and getting caught up drinking and never come back."

\section{Sharing Circles with High School Teachers and School Staff}

Participating teachers and school staff in all communities noted that they wanted youth to learn about the relationship between tobacco use and cancer and focus on food and nutrition. Teachers and school staff in at least two of the three communities also noted that they wanted youth to learn about cancer prevention, the relationship between marijuana and cancer, genetics, and local statistics on cancer:

"What are we doing right in the Northwest Arctic where cancer incidence and mortality is lower than other regions?"

Teachers noted that they could instruct cancer education in a variety of subjects, such as health, science, language arts, and art. Teachers and school staff in all three communities said that cancer education material most useful to them would be online short videos/visuals each followed by a short lesson plan with an activity. As a sharing circle participant noted: "don't have a DVD, have it online." Teachers and school staff in two of the three communities also said that hands-on activities would be one of the best ways for youth to learn, such as group projects, inviting youth to create public service announcements, or offering youth the opportunity to do their own research. Teachers and school staff in two of the three communities also said that stories would be one of the best ways for youth to learn about cancer, such as a "video of someone who is willing to own itwilling to talk about behaviors that have contributed to their cancer risk" or a "video of people who found cancer early and are cancer survivors."

They also noted that for lessons to be useful, the curriculum would need to be approved at the district level. They also felt that starting cancer education in high school was too late, and that information should be available for $5^{\text {th }}$ and $6^{\text {th }}$ grade students, with curriculum on healthy eating offered to students as young as $1^{\text {st }}$ and $2^{\text {nd }}$ grade.

\section{Lessons Learned}

The sharing circles were an informative community-based strategy that elicited feedback from a variety of community members and key stakeholders. The findings between different circles and communities were overlapping, indicating a robustness of the conclusions. Following the guidance of community contacts was also essential, as these individuals helped to collect parental consent forms, arrange the locations and timing of the sharing circles, recommend recruitment strategies such as radio announcements and flyers, and when appropriate, recommend locations and timing for conducting additional sharing circles.

\section{Limitations}

The sharing circles recorded information from participants who were able to attend and contribute their thoughts however not all community members opted to attend or participate in the sharing circles. Consequently, findings may not be generalizable to the communities as a whole. In addition, four specific stakeholder groups were recruited to participate (high school students, teachers/school staff, community members, and health professionals), who were assumed to be essential voices on the topic. However, there may be additional stakeholder groups that were not specifically recruited, who may become essential to creating or delivering cancer education in the three participating communities.

Continuing to be responsive to community members who reach out for information, engaging with key stakeholders, and fostering relationships remains a challenge given the distance between project team members in Anchorage and communities in the Northwest Arctic. As one community member shared: "Come back to visit-just one visit, we'll nod and agree with everything, come up several times and we'll know you're serious." In addition to existing challenges caused by geographic distance, the global COVID-19 pandemic has made anticipated in-person meetings an impossibility, transitioning all Community Advisory Board meetings to online only, despite sometimes limited bandwidth in rural Alaska. Additionally, all cancer education materials are now planned to be developed for use either in-person or 
via distance, given uncertainties about K-12 education in the 2020-2021 school year.

\section{Discussion}

Given the concern about cancer in the three participating communities, and overwhelming interest in learning more about cancer prevention and control among sharing circle participants, this project is a promising first step to developing cancer education for youth in the Northwest Arctic. In addition, 24 sharing circle participants offered to become part of the Community Advisory Board (CAB) to guide the development of cancer education for youth, indicating a long-term commitment to the project. The project team and $\mathrm{CAB}$ will pursue realizing the requests that community members articulated during the sharing circles, including developing a website with audio/visuals and lesson plans. The team plans to develop, implement, and evaluate the culturally relevant online cancer education. The COVID-19 pandemic has further necessitated reliance on the $\mathrm{CAB}$ to point the team in new directions, and a cancer education social media campaign to reach out to youth outside of the school setting is also planned as a next step.

\section{Conclusion}

Sharing circle findings demonstrate a desire for cancer education for youth in the three participating communities. We also learned that sharing circles were an effective way to elicit ideas among the participating individuals, including community members, students, teachers/school staff, and CHA/Ps. In addition, while there were similarities among the sharing circle participants' perspectives, there were also diverse opinions, which emphasizes the need to reach out to multiple groups within communities to formulate an effective, relevant, multi-faceted, and holistic cancer education curriculum. Continuing to work with guidance from community members will also hopefully assist in long-term sustainability within the communities and educational systems that would facilitate the material being used to help reduce cancer incidence and mortality in rural Alaska. Sharing circle responses identified a priority to develop online cancer education that addresses topics such as mitigating cancer risk factors and preventing cancer, including reducing tobacco use, eating healthy foods, physical activity, getting vaccinated against HPV, and getting recommended cancer screenings. Additionally, participating sharing circle respondents identified a need for local statistics on cancer, for information to be shared in ways that are visual, and to share content through story. These findings resonate with previous research in distance delivered cancer education with Alaska Native people, where cancer education learners have requested similar ways of learning, such as through stories and visuals [15, 16, 31-33]. For example, in a key stakeholder survey of Alaska's Community Health Aides and Community Health Practitioners, respondents asked for ways of learning about cancer that included interactive activities such as quizzes, visuals like videos and pictures, local statistics, and stories [16].

These sharing circle findings are the beginning of interactively co-creating cancer education for youth in alignment with the proposed framework for culturally relevant online cancer education, guided by the principles of CBPAR, informed by Empowerment Theory, and honoring Indigenous Ways of Knowing. This cancer education project will seek to promote wellness with, and for, residents in the Northwest Arctic region of Alaska by empowering youth and inspiring positive behavior change among young people, their families, and their communities, to both reduce cancer risk and support those who face cancer. As young people shared:

$$
\begin{aligned}
& \text { "it is useful if it can inform other people." } \\
& \text { "If I learn, I can reduce the chance of getting cancer } \\
& \text { in the future." }
\end{aligned}
$$

Acknowledgements Thank you to the Sharing Circle participants for sharing their thoughts and to the Community Advisory Board who has helped guide this project.

Funding This work is part of "Community engaged development of cancer education for Alaska Native youth," funded by the Alaska Native/American Indian Clinical and Translational Research Program, supported by the National Institute of General Medical Sciences of the National Institutes of Health under Award Number U54GM115371.

\section{Declarations}

Informed Consent The project was reviewed by the University of Alaska Anchorage Institutional Review Board (\#1416366-8) and Maniilaq Association, the tribal non-profit corporation in the Northwest Arctic that manages health, tribal, and traditional assistance programs, as well as social services for the region.

Conflicts of Interest The authors declare no competing interests.

Financial Disclosure The authors have no financial relationships relevant to this article to disclose.

\section{References}

1. Siegel RL, Miller KD, Jemal A (2020) Cancer statistics, 2020. CA Cancer J Clin 70:7-30. https://doi.org/10.3322/caac.21590

2. Centers for Disease Control and Prevention (CDC) (2017) Leading causes of death. In: National Center for Health Statistics. https:// www.cdc.gov/nchs/fastats/leading-causes-of-death.htm. Accessed 14 Jan 2019 
3. Blake I, Holck P, Provost EM (2016) Alaska Native Mortality Update: 2009-2013. Alaska Native Epidemiology Center, Anchorage

4. Nash SH, Redwood DG (2017) Potentially preventable cancers diagnosed among Alaska Native people. Cancer Health Disparities 2:e1-e15. https://doi.org/10.9777/chd.2018.10001

5. Carmack AM, Schade TL, Sallison I et al (2015) Cancer in Alaska Native people: 1969-2013, The 45 Year Report. Alaska Native Tumor Registry, Alaska Native Epidemiology Center, Alaska Native Tribal Health Consortium

6. (2019) Cancer mortality. Alaska Native Tribal Health Consortium Epidemiology Center

7. Nash SH, Meisner ALW, Zimpelman GL et al (2018) Cancer survival among Alaska Native people. Cancer 124:2570-2577. https://doi.org/10.1002/cncr.31350

8. (2017) National survey reveals most Americans are unaware of key cancer risk factors. In: ASCO. https://www.asco.org/advoc acy-policy/asco-in-action/national-survey-reveals-most-ameri cans-are-unaware-key-cancer-risk. Accessed 14 Jan 2019

9. Behavioral Risk Factor Surveillance System, Alaska Department of Health and Social Services, Division of Public Health, Section of Chronic Disease Prevention and Health Promotion (2018) AKIBIS - Query result - Alaska's Behavioral Risk Factors Surveillance System - (BRFSS_C) Query Module - Obesity (30+ BMI). http://ibis.dhss.alaska.gov/query/result/BRFSS23/BRFSS_C/ XBMIOB.html. Accessed 14 Jan 2019

10. Cueva K, Cueva M, Revels L, Dignan M (2018) Culturally-relevant online education improves health workers' capacity and intent to address cancer. J Community Health 1-7. https://doi. org/10.1007/s10900-018-0465-5

11. Cueva K, Revels L, Cueva M et al (2017) Culturally-relevant online cancer education modules empower Alaska's community health aides/practitioners to disseminate cancer information and reduce cancer risk. J Cancer Educ. https://doi.org/10.1007/ s13187-017-1217-4

12. Alaska Native Tribal Health Consortium, Alaska Native Epidemiology Center (2019) Adult mammogram breast cancer screening. http://anthctoday.org/epicenter/healthData/factsheets/Preventati veCare/Breast_Cancer_Screening_02_13_2019.pdf. Accessed $7 / 24 / 2021$

13. Alaska Native Tribal Health Consortium, Alaska Native Epidemiology Center (2019) Adult cervical cancer screening. http://anthc today.org/epicenter/healthData/factsheets/PreventativeCare/Cervi cal_Cancer_Screening_02_13_2019.pdf. Accessed 7/24/2021

14. Alaska Native Tribal Health Consortium, Alaska Native Epidemiology Center (2019) Adult colorectal cancer screening. http://anthctoday.org/epicenter/healthData/factsheets/Preventati veCare/Colorectal_Cancer_Screening_02_13_2019.pdf. Accessed $7 / 24 / 2021$

15. Cueva K, Cueva M, Revels L et al (2018) A framework for culturally relevant online learning: lessons from Alaska's tribal health workers. J Cancer Educ. https://doi.org/10.1007/ s13187-018-1350-8

16. Cueva K, Revels L, Kuhnley R et al (2015) Co-creating a culturally responsive distance education cancer course with, and for, Alaska's community health workers: motivations from a survey of key stakeholders. J Cancer Educ. https://doi.org/10.1007/ s13187-015-0961-6
17. Taualii M, Bush N, Bowen DJ, Forquera R (2010) Adaptation of a smoking cessation and prevention website for urban American Indian/Alaska Native youth. J Cancer Educ 25:23-31. https://doi. org/10.1007/s13187-009-0004-2

18. Lines L-A, Division YDFNW, Jardine CG (2019) Connection to the land as a youth-identified social determinant of Indigenous Peoples' health. BMC Public Health 19:176. https://doi.org/10. 1186/s12889-018-6383-8

19. McConnell S (2013) Culturally tailored postsecondary nutrition and health education curricula for indigenous populations. Int $\mathbf{J}$ Circumpolar Health 72: https://doi.org/10.3402/ijch.v72i0.21144

20. Shaw JL, Beans JA, Comtois KA, Hiratsuka VY (2019) Lived experiences of suicide risk and resilience among Alaska Native and American Indian people. Int J Environ Res Public Health 16: https://doi.org/10.3390/ijerph16203953

21. Glanz K, Rimer BK, Viswanath K (2015) Health behavior: theory, research, and practice, 5th edn. Jossey-Bass, San Francisco

22. Wallerstein NB, Duran B (2006) Using community-based participatory research to address health disparities. Health Promot Pract 7:312-323. https://doi.org/10.1177/1524839906289376

23. Cajete G (1994) Look to the mountain: an ecology of indigenous education, 1st edn. Kivaki Press, Durango

24. Cueva M, Kuhnley R, Cueva K (2012) Enhancing cancer education through the arts: building connections with Alaska Native people, cultures and communities. Int J Lifelong Educ 31(3)

25. Wallerstein N, Bernstein E (1988) Empowerment education: Freire's ideas adapted to health education. Health Educ Q 15:379-394

26. Prussing E (2014) Historical trauma: politics of a conceptual framework. Transcult Psychiatry 51:436-458. https://doi.org/10. 1177/1363461514531316

27. Chávez V, Minkler M, Wallerstein N, Spencer M (2010) Community organizing for health and social justice. In: Prevention is primary, 2nd edn. Jossey-Bass, San Francisco, pp 87-112

28. Perkins DD, Zimmerman MA (1995) Empowerment theory, research, and application. Am J Community Psychol 23:569-579

29. Zimmerman MA (1995) Psychological empowerment: issues and illustrations. Am J Commun Psychol 23:581-599. https://doi.org/ 10.1007/BF02506983

30. Healey Akearok G, Cueva K, Stoor JPA et al (2019) Exploring the term "Resilience" in arctic health and well-being using a sharing circle as a community-centered approach: insights from a conference workshop. Social Sciences 8:45. https://doi.org/10.3390/ socsci8020045

31. Cueva M, Kuhnley R, Lanier AP, Dignan M (2006) Story: the heartbeat of learning cancer education for Alaska Native community healthcare providers. Convergence 39:81-89

32. Cueva M, Kuhnley R, Revels LJ et al (2013) Bridging storytelling traditions with digital technology. Int J Circumpolar Health 72. https://doi.org/10.3402/ijch.v72i0.20717

33. Cueva M, Kuhnley R, Lanier A et al (2016) Promoting culturally respectful cancer education through digital storytelling. Int J Indig Health 11:34-49. https://doi.org/10.18357/ijih111201616013

Publisher's Note Springer Nature remains neutral with regard to jurisdictional claims in published maps and institutional affiliations. 